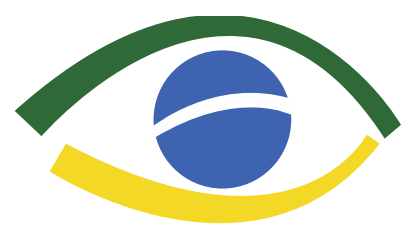

\section{Observatório da Uurisdiçãc Constitucional}

Observatório da Jurisdição Constitucional. Ano 6, no. 2, jul./dez 2013. ISSN 1982-4564.

\title{
Democracia versus Constitución (¿Precompromiso o paternalismo?)
}

\section{Macario Alemany García*}

Resumen: En este artículo se presenta, en primer lugar, la forma de un argumento, central en la defensa de la forma constitucional, que el autor denomina "argumento paternalista". En segundo lugar, se considera su plausibilidad en relación con la justificación de la rigidez constitucional y se trata de interpretar a partir de él la extendida concepción de las constituciones como mecanismos de precompromiso. En tercer lugar, se considera el alcance de dicho argumento paternalista en relación con el control jurisdiccional de constitucionalidad. Al respecto, se sostiene que tal forma de argumentar no supone necesariamente, como afirman algunos destacados defensores de la posición democrática, un "insulto" para los ciudadanos. Finalmente, se concluye en una defensa del constitucionalismo basada en la idea de que los argumentos paternalistas tienen su espacio en una teoría no ideal de la justicia, es decir, su plausibilidad depende, por un lado, del contexto, de la situación $\mathrm{y}$, por otro lado, de algunas máximas de experiencia muy fuertemente asentadas sobre cómo es el mundo y cómo somos los seres humanos.

Palabras clave: Democracia, constitución, precompromiso, paternalismo, rigidez constitucional, control jurisdiccional de constitucionalidad.

\begin{abstract}
The article surveys a specific legal argument called by the author as "paternalistic argument", analyzing (i) the use of this argument in constitutional adjudication, (ii) the congruence of this argument with rigid constitutions, seen as precommitment mechanisms and (iii) the scope of the paternalistic argument in relation to constitutional adjudication. The text defends that the paternalistic argument is not incompatible with democracy. Finally, the article sustains that a constitutionalism based on the idea of paternalistic argument has its place in non-ideal theory of justice.
\end{abstract}

Keywords: democracy, precommitment, paternalistic argument, constitutional adjudication

\footnotetext{
${ }^{\times}$Este trabajo ha sido realizado en el marco del proyecto de investigación DER2010-21032, financiado por el Ministerio de Ciencia e Innovación.

* Doctor en Derecho por la Universidade de Alicante (UA). Profesor Titular en el departamento de Filosofía del Derecho de la Universidad de Alicante (UA).
} 


\section{Introducción}

Uno de los temas centrales de discusión en la iusfilosofía actual es el del constitucionalismo. Este término muestra, en la actualidad, tres acepciones principales: alude a un proceso histórico de proliferación de Constituciones formales; a la práctica de un modelo o ideal político constitucionalista; o, finalmente, a una forma de interpretar los anteriores fenómenos, esto es, a una determinada concepción del Derecho ${ }^{1}$. Las Constituciones formales son Constituciones escritas, cuyo procedimiento de reforma está fuera del alcance del legislador ordinario y que ocupan una posición jerárquica superior a la ley². El ideal constitucionalista puede resumirse en el enunciado del art. 16 de la Declaración de derechos del hombre y del ciudadano de 1789: "una sociedad en la que la garantía de los derechos no está asegurada, ni la separación de poderes está determinada, no tiene una Constitución”. Las relaciones entre ambas nociones de Constitución se pueden introducir, siguiendo a Aguiló, mediante la distinción entre "darse (o tener) una Constitución” y "vivir en Constitución"33. Un sistema jurídico-político "tiene una Constitución”, explica Aguiló, cuando cuenta con una forma constitucional (codificada, rígida y con superioridad jerárquica a la ley) como mecanismo de la garantía de los derechos, pero sólo "vive en Constitución” cuando esos ideales son practicados ${ }^{4}$. Parece bastante obvio que la forma constitucional no es una condición suficiente de la vida en Constitución, pero queda abierta la cuestión de su valor como instrumento para garantizar la práctica de los ideales del constitucionalismo. No obstante las anteriores distinciones, conviene advertir de que en la discusión contemporánea se entiende por "Estado constitucional" aquel que, entre otras características, tiene una Constitución rígida con control jurisdiccional de constitucionalidad $\mathrm{y}$, paralelamente, por “constitucionalismo" se suele entender la defensa de dicho Estado como modelo jurídicopolítico 5 .

El mecanismo de la forma constitucional como garantía de los derechos y libertades básicos ha sido criticado por quienes consideran que supone una limitación injustificable a la soberanía del pueblo, expresada a través de sus representantes en el Parlamento, o que

\footnotetext{
${ }^{1}$ Se suele usar la expresión "neoconstitucionalismo" para referirse tanto al proceso de constitucionalización a partir de la Segunda Guerra Mundial, como para ciertas concepciones del Derecho a partir de este proceso; distinguiéndolo de esta manera del "constitucionalismo" anterior a la guerra. En el presento trabajo utilizaré la expresión "constitucionalismo" en lugar de la de "neoconstitucionalismo". Vid. ATIENZA: 2007: 114 y ss.

${ }^{2}$ Vid. AGUILÓ: 2004: 34 y 35.

${ }^{3}$ Vid. AGUILÓ: 2004: 42; y AGUILÓ: 2008: 132 y ss.

${ }^{4}$ Vid. AGUILÓ: 2004: 42.

${ }^{5}$ Vid. ATIENZA: 2007: 114 y ss.; y GUASTINI: 2003: 49 y ss.
} 
perjudica estructuras jurídicas fundamentales para la convivencia pacífica como la del "imperio de la ley". Autores como Waldron o Laporta han presentado argumentos en este sentido de una forma profunda y sistemática $^{6}$. En consecuencia, en torno al constitucionalismo, uno de los hilos de la discusión se ha concretado en una oposición entre democracia y Constitución, entendida la primera, la posición democrática, como la defensa de la primacía de la representación parlamentaria y la regla de la mayoría ya sea frente al poder constituyente, ya sea frente al poder contramayoritario de los jueces constitucionales y la segunda, la Constitución, como la defensa del mecanismo de rigidez constitucional y el control jurisdiccional de constitucionalidad frente a las eventuales mayorías parlamentarias. Entre algunos partidarios de la rigidez constitucional, se ha tratado de superar esta oposición mediante la concepción de las Constituciones como mecanismos de precompromiso, es decir, como el resultado de compromisos previos del propio pueblo de atarse a sí mismo en la forma constitucional. En la defensa de esta posición cabe destacar a Holmes ${ }^{7}$ o, entre nosotros, a Moreso $^{8}$. Mientras que los partidarios de la democracia (en el sentido al que se aludía) han replicado que se trata de paternalismo y no precompromiso.

Pues bien, en este artículo quisiera presentar, en primer lugar, la forma de un argumento que me parece central en la defensa de la forma constitucional y que denominaré “argumento paternalista". En segundo lugar, consideraré su plausibilidad en relación con la justificación de la rigidez constitucional y trataré de de interpretar a partir de él la extendida concepción de las constituciones como mecanismos de precompromiso. En este sentido, sostendré que hasta cierto punto tienen razón los partidarios de la democracia frente al constitucionalismo al denunciar que el discurso del precompromiso encubre un argumento paternalista. Sin embargo, defenderé que el argumento paternalista no debe ser desechado sin más y cabe sostener su plausibilidad en una justificación de la rigidez constitucional. En tercer lugar, consideraré el alcance de dicho argumento paternalista en relación con el control jurisdiccional de constitucionalidad. Al respecto sostendré que tal forma de argumentar no supone necesariamente, como afirman algunos destacados defensores de la posición democrática, un "insulto" para los ciudadanos. Finalmente, concluiré en una defensa del constitucionalismo basada en la idea de que los argumentos paternalistas tienen su espacio en una teoría no ideal de la justicia, es decir, su plausibilidad depende, por un lado, del contexto,

\footnotetext{
${ }^{6}$ Vid. WALDRON: 2005; y LAPORTA: 2007.

${ }^{7}$ Vid. HOLMES: 1988

${ }^{8}$ Vid. MORESO: 2009.
} 
de la situación y, por otro lado, de algunas máximas de experiencia muy fuertemente asentadas sobre cómo es el mundo y cómo somos los seres humanos.

\section{El "argumento paternalista"}

Por "argumento paternalista" voy a entender un argumento práctico", cuya conclusión es la imposición de una medida política, jurídica, sanitaria, etc., a un individuo, grupo, comunidad, etc., (en adelante, me referiré a quién se le impone la medida paternalista como sujeto B), la cual se presenta como necesaria para (I) evitar daños a B, dada (II) la constatación de un déficit de comprensión o voluntad en el sujeto $\mathrm{B}^{10}$. Ordenado como una secuencia de premisas y conclusión, el argumento podría presentarse de la siguiente manera:

(I) Q constituye el objeto de un deseo, un interés o una necesidad de B.

(II) $\mathrm{X}$ es una medida idónea y necesaria para conseguir, garantizar o promover Q para B.

(III) $\mathrm{B}$ muestra un déficit de comprensión y/o voluntad sobre la necesidad de X.

(IV) Es permisible (u obligatorio) imponer a B la medida $\mathrm{X}^{11}$.

Hart nos proporciona un ejemplo de este tipo de "argumento paternalista" cuando desarrolla su tesis de la existencia de un "contenido mínimo de Derecho natural"12. Hart señala que "dada la supervivencia como objetivo, el derecho y la moral deben incluir un contenido específico" "13. Más adelante, este autor enumera una serie de hechos, los cuales afirma que constituyen "verdades obvias", entre los cuales está el hecho de la "comprensión

\footnotetext{
${ }^{9}$ Sigo el concepto de argumento práctico expuesto en ATIENZA: 2006: 190 y ss.

${ }^{10}$ He tratado de la extensa discusión sobre el concepto de paternalismo en ALEMANY: 2006.

${ }^{11}$ El "argumento paternalista" tiene forma aunque no sea, claro está, un "argumento formal". Siguiendo a Manuel Atienza, entiendo por "forma" aquello que queda tras un proceso de abstracción, esto es, aquello que queda después de "separar o no tomar en cuenta ciertos aspectos de una realidad que se trata de estudiar" (ATIENZA: 2006: 112). Por "argumento formal" se entiende el resultado de una abstracción radical (la formalización) que se expresa exclusivamente a través de las variables y juntores de la lógica. En este caso, la forma del argumento paternalista es el resultado de presentarlo de una forma general (se presenta con cierto grado de abstracción), de manera que podemos reconocer dicha forma en una gran variedad de argumentos más concretos. Tal y como está presentado, se trataría de un argumento cuyo uso es recurrente en la filosofía jurídica y política. Su estudio se situaría en el nivel de una concepción material y pragmática de la teoría de la argumentación. Manuel Atienza explica este enfoque material diciendo que no hace completa abstracción del contenido de los argumentos y del contexto en el que los mismos tienen lugar, constituyendo una "teoría de las premisas o de las buenas razones". Vid. ATIENZA: 2006: 182 y ss.

${ }^{12}$ Vid. HART: 1963: 239 y ss.

${ }^{13}$ Vid. HART: 1963: 239.
} 
y fuerza de voluntad limitadas" de la humanidad ${ }^{14}$. Finalmente, en relación con este hecho, Hart concluye que

Todos sienten la tentación, a veces, de preferir sus propios intereses inmediatos $\mathrm{y}$, en ausencia de una organización especial que descubra y castigue las faltas, muchos sucumbirían a la tentación. Es indudable que las ventajas de las abstenciones mutuas son tan palpables, que el número y la fuerza de los que cooperan voluntariamente dentro de un sistema coercitivo serán normalmente mayor que cualquier combinación probable de transgresores. Sin embargo, salvo en sociedades con una cohesión muy estrecha, la sumisión al sistema de limitaciones sería una insensatez si no hubiera una organización para coercionar a aquellos que tratarían de obtener las ventajas del sistema sin someterse a sus obligaciones. Hacen falta 'sanciones', por lo tanto, no como el motivo normal para la obediencia, sino como una garantía de que aquellos que obedecen voluntariamente no serán sacrificados a quienes no lo hacen. Si no hubiera tal organización, obedecer sería arriesgarse a tener la peor parte. Dado este peligro, lo que la razón reclama es cooperación voluntaria dentro de un sistema coercitivo ${ }^{15}$.

Para Hart, se trataría aquí de una necesidad natural, en el sentido de que su "verdad depende de que los seres humanos y el mundo en que viven conserven las características salientes que hoy tienen" ${ }^{\prime \prime}$. Esto último es importante porque explica la idea de que el argumento paternalista puede arribar a un "deber ser" que no es un simple deber ser técnico, pues, de alguna forma ni el propósito inicial puede no tenerse (la supervivencia), ni las circunstancias del contexto pueden alterarse. La razón que aporta el argumento paternalista sería, de acuerdo con la conocida clasificación kantiana, una razón hipotético-asertórica.

El argumento hartiano podría esquematizarse de la siguiente manera:

\footnotetext{
${ }^{14}$ Vid. HART: 1963: 244.

15 HART: 1963: 244 y 245. En el párrafo citado, Hart presenta conjuntamente dos argumentos que ya están presentes en Hobbes en su clásica respuesta a la pregunta del Tonto: ¿Por qué debo ser justo y cumplir lo pactado, aun cuando también perjudica mis intereses? A este respecto, Zimmerling señala que de acuerdo con Hobbes "es racional cumplir con lo racionalmente acordado siempre que se tenga la garantía de que también las otras partes contratantes lo cumplirán. Según Hobbes, esta condición de cumplimiento universal podría satisfacerse, desde luego, sólo si existiera un poder dotado de medios coactivos suficientes (...) La amenaza de sanciones coactivas para el caso de la violación de un contrato cumple aquí dos funciones: por una parte, un individuo A puede estar seguro de que sus 'socios' no tendrán ningún motivo para violar el contrato, ya que ello les resultaría costoso; queda así satisfecho el presupuesto hobbesiano para el cumplimiento del contrato por parte de A. Pero, por otra, cambia también - para decirlo en términos modernos- el resultado del cálculo de costos y beneficios que hace A de sus propias alternativas de comportamiento; en muchos casos, sólo así pierde atractivo la alternativa del polizón, porque A sabe que ya no podrá obtener beneficio alguno de su violación del contrato cuando los otros lo cumplen". Vid. ZIMMERLING, 1989, 50.

${ }^{16}$ Vid. HART: 1963: 247
} 
(I) Una comunidad humana quiere evitar su extinción.

(II) El establecimiento de un sistema coercitivo es una medida idónea y necesaria para garantizar la supervivencia.

(III) Dicha comunidad muestra una comprensión y fuerza de voluntad limitadas sobre la necesidad de un sistema coercitivo.

(IV) Debe imponerse un sistema coercitivo.

Otro ejemplo de la misma forma de argumento lo encontramos en Tocqueville. Este autor niega que el pueblo elija a los mejores gobernantes, ya que

Es imposible, hágase lo que se haga, elevar la cultura del pueblo por encima de cierto nivel. Por más que se facilite el acceso a los conocimientos humanos, se mejore el nivel de la enseñanza (...) La mayor o menor facilidad que encuentra el pueblo para vivir sin trabajar constituye, pues, el límite insalvable de sus progresos intelectuales (...) Estoy dispuesto a admitir sin dificultad que la masa de los ciudadanos quiera sinceramente el bien del país, y aún iré más lejos: las clases inferiores de la sociedad me parece que mezclan en general a ese deseo menos maquinaciones de interés personal que las clases elevadas: pero lo que siempre les falta en mayor o menor grado es el arte de juzgar los medios, aun queriendo sinceramente el fin ${ }^{17}$.

A lo que añade, que "no siempre es capacidad lo que le falta a la democracia para elegir hombres de mérito, sino deseo o inclinación""18, por la envidia. Concluyendo, "que veo en el doble grado electoral el único medio de poner el uso de la libertad política al alcance de todas las clases del pueblo"19.

17 TOCQUEVILLE: $2002^{a}: 290$.
18 Ídem.
${ }^{19}$ Vid. TOCQUEVILLE: $2002^{a}$ : 295 . En La democracia en América abundan los argumentos de este tipo, por
ejemplo: "[Los padres fundadores] juzgaron que era preciso que, además del pueblo, hubiera un cierto número
de poderes que sin ser completamente independientes de él, gozasen dentro de su esfera, de un grado de libertad
bastante amplio, de tal suerte que, obligados a someterse a la dirección permanente de la mayoría, pudieran sin
embargo luchar contra sus caprichos y negarse a sus peligrosas exigencias. A tal efecto, concentraron todo el
poder ejecutivo de la nación en una sola mano, dieron al presidente amplias prerrogativas y le armaron del veto
para resistir los atropellos de la legislatura" (pp. 206 y 207); "Esta dificultad que encuentra la democracia para
vencer las pasiones y acallar sus necesidades del momento con vistas al futuro se observa en los Estados Unidos
hasta en las menores cosas. El pueblo, rodeado de aduladores, difícilmente logra triunfar de sí mismo. Cuando se
quiere obtener de él que se imponga una privación o una molestia, incluso para un fin que su misma razón
apruebe, casi siempre empieza negándose (...) Así, es de creer, que una ley molesta, cuya utilidad inmediata no
sintiese la mayoría, no sería aprobada o no sería obedecida" (p. 327); "Yo no conozco más que un medio para
impedir que los hombres se degraden: el de no conceder a nadie, con la omnipotencia, el poder soberano de
envilecerle" (p. 347$)$; "Lo que en los Estados Unidos se llama república es el reinado tranquilo de la mayoría. La
mayoría, una vez se ha reconocido a sí misma y ha comprobado su existencia, es la fuente común de todos los
poderes. Pero la mayoría en sí no es todopoderosa. Por encima de ella, en el mundo moral, se hallan la 
Ordenado esquemáticamente, el argumento de Tocqueville sería el siguiente:

(I) El pueblo quiere garantizar la elección de los mejores gobernantes.

(II) Sólo pueden elegir a los mejores gobernantes quienes están versados en el "arte de juzgar los medios" y libres de emociones como la envidia.

(III) El pueblo no puede estar versado en el arte de juzgar los medios y, con frecuencia, está dominado por la envidia.

(IV) El pueblo no debe elegir a los gobernantes directamente.

Finalmente, un tercer ejemplo de esta forma de "argumento paternalista" es sostenido por Mill:

La idea de una democracia racional no consiste en que gobierne el propio pueblo, sino en que éste tenga la seguridad de un buen gobierno. Seguridad que no puede tener de otro modo que reteniendo en sus manos el control último (...) Pero éste es el único propósito por el que es bueno confiar poder al pueblo (...) El control de un hombre sobre su médico no es insignificante, aunque no ordene al médico qué medicina debe administrar. Obedece la prescripción de su médico o, si no está satisfecho con él, llama a otro. En eso consiste su seguridad. En eso consiste también la seguridad del pueblo; y con eso se satisface su inteligencia. Pero como, en todo lo demás, consiste el peligro al gobernar en que aquellos que pueden hacer lo que quieren, pueden querer hacer más de lo que corresponde a su interés último. El interés del pueblo estriba en elegir como sus gobernantes a las personas más instruidas y capaces que se pueda encontrar y, tras haber hecho esto, permitirles ejercitar su saber y su habilidad a favor del bien del pueblo, libremente o con el menor control posible, en la medida en que sea el bien del pueblo, y no algún fin privado, la meta a la que se dirijan ${ }^{20}$.

De nuevo, presentado el argumento como una secuencia de premisas y conclusión, adoptaría la siguiente forma:

(I) El pueblo quiere garantizar un buen gobierno.

(II) Para garantizar un buen gobierno es necesario que gobiernen hombres instruidos y que lo hagan libremente.

(III) El pueblo no está constituido mayoritariamente por hombres suficientemente instruidos para el buen gobierno.

humanidad, la justicia y la razón, y en el mundo político, los derechos adquiridos. La mayoría reconoce estas dos barreras, y si en ocasiones se las salta es porque tiene pasiones como todo ser humano, y porque a semejanza de él es capaz de hacer el mal aunque distinga el bien" (p. 564).

${ }^{20}$ MILL: 1991: 276 y 277. 
(IV) El pueblo no debe gobernar directamente por sí mismo, sino limitarse a elegir representantes, hombres instruidos, y dejarlos gobernar libremente.

\section{El argumento paternalista y la rigidez constitucional}

\subsection{Un coto vedado por razones paternalistas}

El argumento paternalista es más persuasivo cuando apoya medidas que aparecen como una necesidad natural, o casi natural, dadas las circunstancias y los propósitos que generalmente se les adscriben a los seres humanos. En el ámbito político y jurídico, esta forma de fundamentar medidas ha sido central en la teoría de las necesidades básicas ${ }^{21}$. Hart, como hemos visto, se circunscribe al propósito de supervivencia para afirmar que dicho propósito, junto con algunas verdades obvias, fundamenta, entre otras cosas, el respaldo coactivo de las normas jurídicas. Hart practica una fuerte auto-restricción, de manera que el conjunto de esas necesidades naturales (del contenido mínimo de Derecho natural) es muy pequeño. Pero basta con incluir, junto al objetivo de la supervivencia, el objetivo del bienestar, para que el conjunto de necesidades naturales, o necesidades básicas, se amplíe: Garzón Valdés, por ejemplo, define a las necesidades básicas como "aquellas cosas o estados de cosas que son buenas por ser condición necesaria de la existencia humana o de su bienestar",22. Dentro de este conjunto, Garzón Valdés incluye también a aquellas que "son indispensables para vivir con dignidad en una sociedad determinada"23.

La teoría de las necesidades básicas explicaría el carácter hipotético-asertórico de los razonamientos anteriores, porque convierte la primera premisa del argumento paternalista en interés objetivo de los seres humanos, en algo que racionalmente no puede ser no querido, dados los últimos e inamovibles objetivos de la supervivencia y el bienestar. Este punto se ilustra perfectamente con la defensa que Garzón Valdés hace de su doctrina del "coto vedado". Como es sabido, Garzón Valdés denomina "coto vedado" al conjunto de "todos aquellos bienes que son considerados como básicos para la realización de todo plan de vida" ${ }^{24}$. En una democracia constitucional, este conjunto está excluido de la negociación y el compromiso parlamentario. La determinación del campo de exclusión, explica Garzón

\footnotetext{
${ }^{21}$ Vid. AÑÓN: 1994.

${ }^{22}$ GARZÓN: $1993^{\mathrm{a}}$ : 425.

${ }^{23}$ GARZÓN: 1994: 740.

${ }^{24}$ GARZÓN: 1993b: 644.
} 
Valdés, "no puede quedar librada al consenso fáctico ni de los representantes ni de los representados" 25 . En cuanto a la vigencia efectiva de los derechos en el "coto vedado" de los bienes básicos, "es indiferente la voluntad o los deseos de los integrantes de la comunidad"26. Por lo cual, afirma Garzón Valdés:

Aquí está plenamente justificada una actitud paternalista en el caso de que los miembros de la comunidad no comprendan la importancia de estos bienes básicos. Y ello es así porque la no aceptación de la garantía de los propios bienes básicos es una clara señal de irracionalidad o de ignorancia de las relaciones causales elementales como son las que existen entre la disponibilidad de estos bienes y la realización de cualquier plan de vida. En ambos casos, quien no comprende la relevancia de los bienes básicos puede ser incluido en la categoría de incompetente básico ${ }^{27}$.

En la doctrina de Garzón Valdés sobre el coto vedado hay dos tesis: Una primera tesis presenta un conjunto acotado utilizando para ello la teoría de las necesidades básicas: el deslinde, por seguir con la metáfora del coto, es posible porque podemos seguir la línea que separa las necesidades básicas de otras cosas. Una segunda tesis declara vedado el coto, utilizando para ello un argumento paternalista:

(I) La comunidad humana quiere garantizarse el disfrute de los bienes incluidos en el coto.

(II) Para garantizarse el disfrute de los bienes incluidos en el coto es necesario que la comunidad humana no pueda no quererlos.

(III) La comunidad humana puede no querer los bienes del coto por irracionalidad o ignorancia de las relaciones causales elementales.

(IV) El coto debe ser vedado, esto es, no puede quedar librado al consenso fáctico ni de los representantes ni de los representados.

Este "argumento paternalista" permite fundar un límite al principio democrático, entendido como regla de la mayoría. Más aún, se diría que la defensa de la democracia constitucional, es decir, aquella que limita la regla de la mayoría por medio de una constitución rígida descansa, en parte, en un argumento de tipo paternalista. Destaco que el argumento paternalista sólo en parte justifica la rigidez constitucional porque dicho argumento apoya la necesidad de vedar del coto, pero no nos dice nada sobre su contenido.

\footnotetext{
${ }^{25}$ GARZÓN: 1993b: 644.

${ }^{26}$ GARZÓN: 1993b: 645.

${ }^{27}$ Ídem.
} 
De ahí que frente a la objeción moral que supone la apelación al principio democrático, el argumento paternalista puede tener muy poca fuerza si dentro del coto ponemos bienes de escasa importancia o elementos que no constituyen bien moral alguno (por ejemplo, el color de la bandera). Pero, a la inversa, el argumento paternalista puede tener mucho peso frente a la objeción democrática, si se trata de proteger efectivamente necesidades básicas o bienes primarios.

Este aspecto paternalista de la rigidez constitucional, ha sido advertido (y criticado) por Laporta para quien la misma se asienta en "un gigantesco acto de paternalismo para el que no saben darse razones de mayor peso que esas limitaciones de la racionalidad" 28 . Laporta tiene razón en que no basta con aludir a esas limitaciones (la premisa III del argumento) para justificar la conclusión, ya que es necesario incluir las demás premisas que conjuntamente aluden a bienes primarios que racionalmente no pueden ser no queridos. Sin embargo, si cabe fundamentar esas otras premisas (cabe deslindar un conjunto de bienes tales que racionalmente no pueden no ser queridos), entonces la crítica de Laporta, en mi opinión, no es aceptable. De hecho, este mismo autor admite que "los principios o razones que recogen derechos individuales básicos o descansan en ellos son lo suficientemente poderosos para medirse con la objeción contramayoritaria"29.

\subsection{El argumento paternalista y la doctrina del precompromiso}

Jon Elster es uno de los autores que más han contribuido a la discusión sobre el alcance y concepto de la noción de precompromiso, compromiso previo o "atarse a sí mismo". De acuerdo con este autor, “atarse a sí mismo es llevar a cabo cierta decisión en el tiempo $t 1$ para aumentar la probabilidad de llevar a cabo otra decisión en el tiempo t2 ${ }^{\text {,30 }}$. El ejemplo clásico de mecanismo de compromiso es el clásico pasaje homérico de Ulises y las Sirenas. En la interpretación que de este pasaje hace Elster, Ulises muestra que

\footnotetext{
${ }^{28}$ LAPORTA: 2001: 464

${ }^{29}$ LAPORTA: 2007: 234. Si bien, Laporta pone inmediatamente el énfasis en lo que considera que no tiene fuerza frente al principio democrático: "La constitucionalización de mecanismos que incrementan la racionalidad instrumental de las decisiones, superando la desviación a que empujan las pasiones, los intereses sectoriales o la miopía temporal sólo podría aceptarse si, como hemos visto en el caso anterior, se llevara a cabo sólo mediante cláusulas de enfriamiento. Sólo cuando esas instituciones fueran un medio para el reconocimiento y la garantía de los derechos individuales o bienes públicos que estén en la base de derechos individuales podría irse más allá" (LAPORTA: 2007: 234).

${ }^{30}$ ELSTER: 1997: 71.
} 
no era por completo racional, pues un ser racional no habría tenido que apelar a este recurso; tampoco era, sencillamente, el pasivo e irracional vehículo de sus cambiantes caprichos y deseos, pues era capaz de alcanzar por medios indirectos el mismo fin que una persona racional habría podido alcanzar de manera directa. Su situación -ser débil y saberlo- señala la necesidad de una teoría de la racionalidad imperfecta que casi ha sido olvidada por filósofos y científicos sociales ${ }^{31}$.

Elster añade que estos mecanismos de compromiso previo "se extienden de la conducta individual a la conducta de grupo; las sociedades, así como los individuos han encontrado útil atarse ellas mismas por medio de constituciones" ${ }^{\text {32. }}$.

Es importante advertir que esta doctrina del precompromiso aplicada a las Constituciones muestra una importante ambigüedad. En primer lugar, la doctrina puede entenderse como la afirmación de que la intención de los constituyentes fue establecer dichos mecanismos de precompromiso. En este caso, para aceptar la doctrina es necesario afirmar la existencia del hecho del precompromiso y por ello, como ha señalado De Lora, esta concepción de la Constitución conduce de forma natural a una concepción "intencionalista" $\mathrm{u}$ "originalista" de la misma, de acuerdo con la cual en la comprensión de la Constitución es primordial la intención(es) o pretensión(es) original(es) que animó a los constituyentes ${ }^{33}$. El alcance justificativo de la doctrina así entendida depende del que estemos dispuestos a otorgarle a la concepción originalista de la interpretación constitucional y, por ende, tiene los mismos límites y es susceptible de las mismas críticas que suelen dirigirse al "originalismo" 34 . Pero no sólo, porque además la analogía entre el precompromiso constitucional y el pasaje de Ulises y la Sirenas, suscita dudas adicionales: En los ejemplos de precompromiso individual vemos, efectivamente, un sujeto ejerciendo su autonomía, tomando decisiones que le atan al futuro, en previsión de su probable comportamiento imprudente. Sin embargo, cuando pasamos al nivel político ya no vemos con claridad ni quién se precompromete (¿puede hablarse del constituyente como un individuo, esto es, como el Ulises en t1?), ni el contenido del mandato (¿qué alcance tiene el compromiso previo del constituyente?), ni la continuidad en el sujeto que se precompromete (¿es la eventual mayoría parlamentaria cuya legislación

\footnotetext{
${ }^{31}$ ELSTER: 1997: 66

${ }^{32}$ ELSTER: 1997: 67.

${ }^{33}$ Vid. DE LORA: 1998.

${ }^{34}$ Sobre las dificultades para apoyar la interpretación de la Constitución como un mecanismo de precompromiso en la intención del constituyente: Vid. DE LORA: 1988; y LIFANTE: 1999.
} 
eventualmente contradice la Constitución el Ulises en t2?). Éstas son razones, entre otras, por las que el propio Elster se ha desdicho de su interpretación inicial de las Constituciones como mecanismos de precompromiso ${ }^{35}$.

En segundo lugar, la doctrina del precompromiso puede entenderse como una dramatización de un modelo de racionalidad que toma en consideración los déficit de racionalidad y/o voluntad de los sujetos reales; la racionalidad imperfecta construida sobre la idea de "ser débil y saberlo" a la que alude Elster. En este caso, dicha doctrina aboga por una interpretación caritativa de los pactos constitucionales, que se contrapone precisamente a las interpretaciones originalistas y cuyo alcance justificativo no depende del hecho de que los constituyentes tuvieran la intención de precomprometerse, sino que precisamente depende de un argumento del tipo del que he llamado aquí "argumento paternalista". Moreso nos ofrece, a mi juicio, un ejemplo de esta forma de argumentar:

El mecanismo del precompromiso -dice este autor- puede contemplarse como una explicación contextual de la primacía de la Constitución; pertenece a las circunstancias en que es posible referirse a la primacía de la Constitución, de forma semejante a como, por ejemplo, David Hume pensaba que la escasez moderada pertenece a lo que pueden denominarse circunstancias de la justicia (...) Si las decisiones colectivas son susceptibles de ser afectadas por la debilidad de las voluntades concurrentes, entonces es razonable pensar en introducir mecanismos procesales para la toma de decisiones que introduzcan la racionalidad indirectamente (..) Los mecanismos de precompromiso están diseñados para que tengamos mayores probabilidades de alcanzar los resultados deseados, por lo que si dichos mecanismos funcionan en las decisiones colectivas tenemos buenas razones para introducirlos en el diseño de nuestras instituciones políticas. La democracia constitucional representa un modelo adecuado de incorporación de dichos mecanismos ${ }^{36}$.

El argumento de Moreso se puede presentar en la forma paternalista de la siguiente manera:

(I) La sociedad política desea maximizar las probabilidades de alcanzar los resultados deseados.

\footnotetext{
${ }^{35}$ Vid. ELSTER: 2002: 186 y ss.

${ }^{36}$ MORESO: 2000: 37.
} 
(II) Para maximizar las probabilidades de alcanzar los resultados deseados por la sociedad política es necesario diseñar mecanismos procesales que promuevan la adopción de decisiones racionales.

(III) La debilidad de la voluntad concurrente de los individuos miembros de la sociedad política puede promover la adopción de decisiones colectivas irracionales.

(IV) Se deben adoptar mecanismos procesales que corrijan el fenómeno de la debilidad de la voluntad concurrente, esto es, mecanismos de precompromiso.

En mi opinión, de estas dos formas de entender la doctrina del precompromiso, la segunda es la que tiene más peso frente a las objeciones democráticas: De hecho, consigue darle la vuelta al argumento de que aceptar la rigidez constitucional supone aceptar la "tiranía de las generaciones pasadas": Ya que dicha tiranía se mostraría, al contrario, cuando al no contar con la rigidez constitucional, se priva a la generación presente de una plausible estrategia de garantía de sus derechos y libertades fundamentales, desatendiendo de esta manera las circunstancias reales de la sociedad, las cuales incluyen el hecho de los déficit de comprensión y/o voluntad en la acción individual y colectiva ${ }^{37}$. Más aún, mientras que en el ámbito individual los mecanismos de precompromiso se muestran como esenciales en la consecución de la felicidad y de los más valiosos logros de la autonomía, en el ámbito político nos veríamos abocados, de acuerdo con la posición democrática, a renunciar a dichas estrategias esenciales. La acción política quedaría constreñida en modelos de racionalidad perfecta cuyos resultados beneficiosos sólo pueden producirse a partir del presupuesto, totalmente irreal, de que los individuos se comportan siempre como sujetos racionales.

\footnotetext{
${ }^{37}$ Ferrajoli ha argumentado de la misma forma a favor de la rigidez constitucional, si bien poniendo el énfasis en la necesidad de salvaguardar los derechos de las generaciones futuras frente a la acción de la generación del presente: "El principio del derecho permanente de todas las generaciones a decidir su futuro se puede utilizar, con aparente paradoja, para apoyar la tesis exactamente opuesta a la de la existencia de un poder constituyente permanente y radical, expresión de la soberanía popular. Puede esgrimirse en apoyo de la tesis según la cual la rigidez de la constitución es justamente expresión y garantía de la soberanía popular de las generaciones futuras y de los propios poderes de las futuras mayorías. Con es base debe impedirse la revisión, al menos, de los principios constitucionales supremos, puestos en defensa permanente de la soberanía popular y de los poderes de la mayoría. Por ejemplo, el método democrático, los derechos políticos y el sufragio universal, los derechos de libertad y quizás los derechos sociales, que forman el presupuesto elemental de los derechos políticos. La rigidez, en otras palabras, ata las manos de las generaciones presentes para impedir que éstas amputen las manos de las generaciones futuras. Esto quiere decir que un pueblo puede decidir, "democrática" y contingentemente, ignorar o destruir la propia constitución y entregarse definitivamente a un gobierno autoritario. Pero no puede hacerlo de forma constitucional, invocando a su favor el respeto de los derechos de las generaciones futuras o la omnipotencia de la mayoría, sin suprimir con ello el método democrático, los derechos y el poder de las mayorías de las generaciones futuras" (FERRAJOLI: 2008: 95 y 96).
} 
En conclusión, podría afirmarse que no tomar en consideración el probable déficit de comprensión y/o voluntad, tanto en la acción individual como política, es irracional. De ahí que manejar un argumento paternalista para apoyar la rigidez constitucional no tiene que ser visto como minusvalorador de los sujetos pretendidamente beneficiados por dicha rigidez. Al contrario, una interpretación caritativa de los pactos constitucionales nos debe llevar a entender que los ciudadanos, como sujetos racionales, han adoptado mecanismos de precompromiso contra su déficit de comprensión y/o voluntad.

\section{El argumento paternalista y el control jurisdiccional de constitucionalidad}

Como ha destacado De Lora, uno de los méritos del pensamiento de Jeremy Waldron es, sin duda, haber tratado de dar cuenta de la tensión entre democracia y constitución, partiendo de los mismos postulados que suelen adscribirse a los defensores de la rigidez y control jurisdiccional de constitucionalidad. De esta manera, Waldron ha evitado caer "en las invectivas de antaño articuladas exclusivamente sobre la creencia en el valor supremo e incontestable de la opinión de la mayoría, o bien sobre el escepticismo radical de la existencia

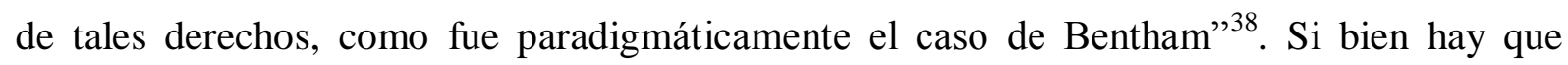
advertir que para Waldron, a partir de la consideración del hecho del desacuerdo en las sociedades modernas, lo que demanda tal concepción de los derechos es que los individuos tengan la oportunidad de participar en la discusión sobre sus límites y contenido esencial, alcanzándose las decisiones por medio de un procedimiento democrático, en particular, por medio de una votación parlamentaria ${ }^{39}$. Reservar, por el contrario, tales procesos de decisión y votación a los tribunales supone - a juicio de este autor- sustituir la mayoría democrática de los representantes de los ciudadanos, por la mayoría no democrática y elitista de los componentes del tribunal. Este dualismo reflejaría, en última instancia, una injustificable desconfianza en los mismos individuos que se trata de proteger, a los que se trataría no como a "dignos pensadores-de-derechos", sino como a "víctimas potenciales cuyos intereses necesitan protección" ${ }^{40}$ y un también injustificable pesimismo antropológico.

Centrándonos en el problema del control jurisdiccional de constitucionalidad, la posición que ilustra la doctrina democrática de Waldron pone el énfasis en "quién decide" (si

\footnotetext{
${ }^{38}$ DE LORA: 1998: 55.

${ }^{39}$ Vid. WALDRON: $1995^{\mathrm{a}}: 277$ y ss.

${ }^{40}$ WALDRON: $1995^{\mathrm{a}}$ : 298.
} 
la amplia mayoría democrática o la mínima mayoría judicial) y presupone un argumento paternalista en la posición constitucionalista, el cual sería en su opinión inaceptable. De forma simétrica, la posición constitucionalista que entiende las constituciones como mecanismos de precompromiso también pone el énfasis en el "quién decide" e, igualmente, presuponen la justificación paternalista si bien la asumen. Ello parece situar el debate en si, en realidad, hay razones para pensar, de un lado, que la mayoría democrática puede comportarse a lo largo del tiempo de forma irracional en relación con sus intereses y, de otro lado, si la elite judicial mantendrá a lo largo del tiempo la actitud y el conocimiento necesarios para preservar dichos intereses. En resumen, esta forma de argumentar sitúa el problema de la justificación del paternalismo como la clave del asunto.

En principio, afirmar que el control jurisdiccional de constitucionalidad constituye un caso de paternalismo justificado otorga una importante ventaja retórica a los partidarios de la democracia, por el carácter peyorativo de dicho término. De ahí que, la mayoría de los autores "constitucionalistas" prefieran hablar de precompromiso y no de paternalismo (evitando así conceder dicha ventaja retórica). Sin embargo, por las razones que he señalado anteriormente en relación con la doctrina del precompromiso, es ineludible enfrentar directamente la cuestión de la validez de un argumento paternalista en apoyo del control jurisdiccional de constitucionalidad.

El elemento más problemático en la justificación del paternalismo en un marco general de respeto por la autonomía es la asimetría que presupone entre el agente paternalista, A, y el sujeto tratado paternalistamente, B. En toda relación paternalista justificada, A muestra alguna cualificación de la que B carece. Cuando se tratan de justificar los aspectos paternalistas del ejercicio de la patria potestad, se presupone que los titulares de dicha potestad son más sabios y prudentes que sus hijos menores, de los cuales se destaca su inmadurez. Análogamente, si el control jurisdiccional de constitucionalidad se apoya en un argumento paternalista será porque los jueces constitucionales reúnen mejores credenciales para llevar a cabo la tarea que se les encomienda que las mayorías parlamentarias. Dicho de otro modo, el argumento paternalista parece presuponer un argumento elitista a favor de los jueces que a muchos les resulta insoportable. La siguiente cita de Waldron ilustra perfectamente esta posición:

¿Cuál es entonces la concepción adecuada en el caso de la participación? El peculiar insulto a un individuo A por ser excluido del poder político tiene que ver, primero, con el 
impacto de las decisiones políticas sobre los propios derechos e intereses de $\mathrm{A}$, y segundo, con que A tenga la capacidad de decidir responsablemente acerca de dichas cuestiones (incluso sabiendo que los propios derechos e intereses de A no son los únicos derechos e intereses en juego) (...) $\mathrm{Y}$ precisamente porque A posee un sentido de la justicia, puede considerar que tiene lo necesario para participar en las decisiones en las que los derechos de los demás están también en juego. Si en cualquier caso A es excluido de la decisión (por ejemplo, porque la decisión final ha sido asignada a una elite aristocrática), A se sentirá menospreciado: sentirá que su propio sentido de la justicia ha sido denigrado como inadecuado para la labor de decidir no sólo algo importante sino algo importante en lo que él, A, tiene un interés en juego igual que los demás. Sentir este insulto no implica necesariamente pensar que su voto, si lo tuviera, le daría un poder significativo y palpable. Sabe que él tiene un derecho a participar, también lo tienen millones de otras personas. Lo único que pide, al menos por lo que respecta a su participación, es que él y todos los demás sean tratados como iguales en asuntos que afectan a sus intereses, a sus derechos y a sus obligaciones ${ }^{41}$.

A mi juicio, sin embargo, es posible encontrar suficientes argumentos que apoyan la tesis de que el tipo de paternalismo que presupone el control jurisdiccional de constitucionalidad (admitiendo, por tanto, que es una forma de paternalismo) está (sin embargo) justificado.

Una primera razón es que esta tensión entre la elite judicial y la mayoría parlamentaria no puede traducirse sin más como una tensión entre la elite y el pueblo. Los espacios de incompetencia para el legislador abren espacios de libertad para los ciudadanos, de manera que la garantía del respeto de los mismos aún atribuida a un pequeño conjunto de jueces no debe ser vista necesariamente por el individuo como una imposición paternalista. El paternalismo se da sobre las eventuales mayorías parlamentarias: es de ellas de quien se predica la tercera premisa del argumento paternalista, esto es, la presencia de déficit de comprensión y/o voluntad. En palabras de John Rawls, los tribunales constitucionales son "antimayoritarios con respecto a la ley ordinaria (...) Sin embargo, la autoridad superior del pueblo lo apoya" ${ }^{\prime 4}$. Por el contrario, el paternalismo que sí parece ejercerse directamente sobre los ciudadanos es el paternalismo legal, puesto que también el legislador puede aprobar leyes paternalistas (por ejemplo, haciendo obligatorio el uso del cinturón de seguridad), en la

\footnotetext{
${ }^{41}$ WALDRON: $1995^{\mathrm{a}}: 284$ y 285.

${ }^{42}$ RAWLS: 1996:269.
} 
medida en que interviene en la conducta auto-referente de los ciudadanos y por su propio bien, sobre el presupuesto de que tales ciudadanos muestran los mencionados déficit de racionalidad y/o voluntad. Para Waldron tal paternalismo ejercido por medio de leyes democráticas es aceptable puesto que, a su juicio, cuenta con el consentimiento previo de los afectados $^{43}$. Sin embargo, hablamos de paternalismo legal sólo cuando se trata de derecho imperativo, es decir, cuando las normas se aplican sea lo que sea lo que los destinatarios, a quien se quiere beneficiar, piensen al respecto. De manera que la situación del ciudadano frente a la ley paternalista es análoga a la situación del legislador frente a la norma constitucional: una situación de incompetencia para modificar su propia situación jurídica al respecto. Si esto es así, Waldron debería admitir como únicos casos de paternalismo jurídico justificado a las normas resultado de la autonomía de la voluntad individual: por ejemplo, a los genuinos contratos Ulises en las que una parte acuerda con la otra que limite alguna opción en el futuro para evitar una probable conducta imprudente, perjudicial, etc., de la primera parte. Pero si Waldron arribara a esta conclusión, su posición se vería debilitada puesto que hay muchos supuestos de legislación paternalista que generalmente se consideran justificados. Por último, se da la paradoja de que autores como Mill y Tocqueville veían en las limitaciones constitucionales a la voluntad del legislador una garantía precisamente contra el paternalismo estatal puesto que, como sabemos, entre estas restricciones constitucionales se incluía el principio liberal de que sólo la conducta que daña a terceros puede ser objeto de normas imperativas ${ }^{44}$. Dicho de otro modo, desde el punto de vista de los ciudadanos, la elite judicial puede constituir incluso un freno contra el paternalismo legal.

\footnotetext{
${ }^{43}$ WALDRON: 2005: 305 y ss.

44 Es muy bien conocida la posición de Mill al respecto, expresada en On liberty, con su declaración de "un sencillo principio", de acuerdo con el cual "la única finalidad por la cual el poder puede, con pleno derecho, ser ejercido sobre un miembro de una comunidad civilizada contra su voluntad, es evitar que perjudique a los demás. Su propio bien, físico o moral, no es justificación suficiente. Nadie puede ser obligado justificadamente a realizar o no realizar determinados actos, porque eso fuera mejor para él, porque le haría feliz, porque, en opinión de los demás, hacerlo sería más acertado o más justo”. Vid. MILL: 1999: 68. Tocqueville, por su parte, con no menos contundencia dice lo siguiente: "Si imagino con qué nuevos rasgos podría el despotismo implantarse en el mundo, veo una inmensa multitud de hombres parecidos y sin privilegios que los distingan incesantemente girando en busca de pequeños y vulgares placeres, con los que contentan su alma, pero sin moverse de su sitio (...) Por encima se alza un poder inmenso y tutelar que se encarga exclusivamente de que sean felices y de velar por su suerte. Es absoluto, minucioso, regular, previsor y benigno. Se asemejaría a la autoridad paterna si, como ella tuviera por objeto preparar a los hombres para la edad viril; pero, por el contrario, no persigue más objeto que fijarlos irrevocablemente en la infancia; este poder quiere que los ciudadanos gocen, con tal de que no piensen sino en gozar. Se esfuerza con gusto en hacerlos felices, pero en esa tarea quiere ser el único agente y el juez exclusivo; provee medios a su seguridad, atiende y resuelve sus necesidades, pone al alcance sus placeres, conduce sus asuntos principales, dirige su industria, regula sus traspasos, divide sus herencias ¿no podría librarle por entero de la molestia de pensar y del trabajo de vivir?”. Vid. TOCQUEVILLE: 2002 : 404 y 405.
} 
La segunda razón es que de la misma manera que al Parlamento le conferimos un valor relativamente independiente de su realidad, del contenido y calidad de las leyes que promulga, a los Tribunales constitucionales les debemos conceder un valor relativamente independiente del contenido y calidad de sus sentencias. Tiene razón Waldron cuando señala que en defensa del constitucionalismo se suele presentar una imagen realista de los Parlamentos y una imagen ideal de los tribunales constitucionales ${ }^{45}$. Las mayorías parlamentarias pueden operar en la práctica con motivos espurios y de modos bastantes alejados del interés general, espoleadas, por ejemplo, por grupos de presión económicos. Ahora bien, también las cortes constitucionales han dado ejemplos deplorables de parcialidad política a lo largo de la historia. De manera que ni los Parlamentos ni las Cortes constitucionales actúan siempre como debieran. Sin embargo, en ambos casos hay que atender tanto a la realidad como a la idealidad de las instituciones.

En el caso de los tribunales constitucionales, dicho valor, relativamente independiente del acierto o desacierto de sus sentencias, tiene que ver sobre todo con las actitudes que promocionan y las exigencias deliberativas y argumentativas que hacen presentes en la práctica jurídica. La tarea de control de constitucionalidad que se asigna a los jueces no es sólo decidir por mayoría si un determinado texto legal vulnera o no la Constitución; presentar así las cosas lleva a ver el asunto como la confrontación de dos mayorías: la del pueblo y la elitista de los jueces. Su tarea es tomar esa decisión a partir de una justificación pública que debe de partir de la Constitución como premisa del razonamiento. Lo que le pedimos a los tribunales constitucionales no es sólo que decidan sobre el límite y contenido esencial de los derechos por mayoría, sino que traten de alcanzar conclusiones de la forma más coherente posible con el Derecho y, esencialmente, que justifiquen dichas conclusiones.

Presuponiendo, como creo que hay que hacerlo, que existen criterios para juzgar la corrección de una argumentación jurídica -algunos argumentos son mejores que otros-, es posible que jueces razonables y experimentados discrepen, lo cual legitima los procedimientos de votación ${ }^{46}$. Dichos procedimientos presuponen el carácter argumentativo del Derecho, las soluciones a los casos difíciles no se demuestran sino que se argumentan, el

\footnotetext{
${ }^{45}$ Esto es lo que Laporta denomina, en relación con la interpretación jurídica, la "falacia del Nirvana", que ocurre cuando, por ejemplo, se contrapone al "famoso juez Hércules de Dworkin, un ser con una densa formación moral y jurídica que puede trabajar sin limitaciones de tiempo ni problemas de acceso a la información, con la imagen que a veces se da de las agencias administrativas como entidades peligrosas y arbitrarias, irremediablemente impregnadas de ambición y tendenciosidad". Vid. LAPORTA: 2007: 192.

${ }^{46}$ Vid. MCCORMICK: 2005.
} 
método jurídico no es esencialmente lógico sino argumentativo. Más profundamente, los procedimientos de votación en el seno de los tribunales (y la posibilidad de discrepar públicamente) reflejan el carácter fundamentalmente práctico de la argumentación del juez, el cual, como ha destacado Atienza, requiere por parte de quien argumenta asumir la "actitud práctica”, esto es, adherirse a las normas y valores que constituyen las premisas de su razonamiento $^{47}$. El juez constitucional debe deliberar con los otros jueces sobre los casos que se les presentan, pero no puede negociar la solución de los mismos: si buscando una unanimidad en la resolución ocultara lo que creen que son mejores razones que las de la mayoría estaría traicionando el compromiso que se le presupone con los valores constitucionales.

Es en esta línea de razonamiento que, Ferreres, a partir de un argumento paternalista ${ }^{48}$, aboga por la rigidez y control judicial de la ley pero no tanto porque produzca directamente seguridad en los derechos a través de un mecanismo jurídico (admitido que el mecanismo falla), sino porque indirectamente

Al expresar los derechos de modo solemne, [la Constitución] recuerda a los miembros de la comunidad política la especial importancia que tienen esos derechos para asegurar a todas las personas una vida mínimamente digna. Al hacer 'visibles' estos elementos básicos de la dignidad, empuja a los representantes a preguntarse si las leyes que proponen están realmente en consonancia con ellos. La Constitución trata de reforzar una cultura pública en la que los derechos generalmente aceptados como fundamentales son tomados en serio en la deliberación colectiva ${ }^{49}$.

Y, concretamente, por lo que respecta al juez constitucional, Ferreres afirma que puede desempeñar un papel relevante, en un doble sentido:

\footnotetext{
47 ATIENZA: 2006: 198 y 199.

${ }^{48}$ Ferreres se pregunta qué sentido tiene (en una democracia) constitucionalizar unos derechos abstractos que la mayoría acepta autónomamente: "La respuesta -nos dice ese autor- tiene que ver con los costes de los derechos fundamentales. Estos derechos no se satisfacen gratuitamente: su garantía efectiva exige el sacrificio de otros intereses, que pueden afectar a una multitud de personas. Puede ocurrir que, por debilidad de la voluntad o por limitaciones cognitivas, la mayoría parlamentaria del momento (aunque actúe de conformidad con la opinión pública mayoritaria) adopte una decisión que lesione un derecho cuya validez y especial peso la propia mayoría (tanto la parlamentaria como la social) reconoce. Del mismo modo que es posible que un individuo actúe de manera disconforme con los principios morales que autónomamente acepta, es posible que la mayoría política lesione ciertos derechos cuya existencia y especial peso acepta autónomamente". Vid. FERRERES: $2000: 36$.

${ }^{49}$ FERRERES: 2000: 36 y 37.
} 
En primer lugar, el proceso de control judicial de la ley ejemplifica de manera especialmente refinada la práctica de argumentar a favor y en contra de las decisiones políticas a partir de razones derivadas de la Constitución (...) En segundo lugar, el juez puede enriquecer el debate con nuevas voces que no pudieron hacerse oír en el proceso legislativo ${ }^{50}$.

La tercera razón presupone reconsiderar el sentido en el que buscamos "mecanismos" que promuevan, en un contexto de justicia procesal imperfecta, en la mayor medida y dada las circunstancias, la garantía de los derechos fundamentales. En mi opinión, la analogía con los "contratos Ulises" ha generado cierta distorsión de la discusión. Waldron agudamente ha señalado que el control jurisdiccional de constitucionalidad se parece más a una estrategia tipo "amigo del conductor borracho" que a un verdadero mecanismo de auto-restricción que hace imposible para el sujeto llevar a cabo cierta acción no deseada (en este caso, tomar decisiones mayoritarias vulneradoras de derechos). De ahí que, al aceptar el control jurisdiccional de constitucionalidad, estaríamos haciendo el análogo de entregar las llaves de la constitucionalidad a un amigo que presuponemos siempre sobrio, cuando el problema es que en esta materia bien puede ser que el Ulises no se haya emborrachado, sino que ha cambiado genuinamente de opinión sobre lo que los derechos fundamentales exigen para ciertos casos. En mi opinión, Waldron tiene una parte de razón, pero no toda.

Waldron tiene razón al señalar que lo que hacen los jueces constitucionales no se parece a un mecanismo, no es un proceso automático que realiza indefectiblemente la voluntad constituyente. Ahora bien, en primer lugar, lo que hacen los jueces constitucionales no se parece a un mecanismo porque el mecanismo está en otro sitio: El mecanismo deriva de la incompetencia que tiene el legislador, supuesto que no nos situamos en el denominado "modelo Westminster", para dictar normas que vulneran en su contenido los límites constitucionales. Atienza y Ruiz Manero han defendido que en las condiciones de validez de la regla que confiere el poder de legislar, no sólo han de incluirse condiciones relativas al procedimiento y a la competencia personal y material (entendida esta última como ámbitos o temas sobre los que puede versar la regulación,), sino también el contenido de la ley conforme a la constitución ${ }^{51}$. De ahí que la aprobación de una Constitución formal sí pueda ser vista como un mecanismo institucional que hace imposible al legislador aprobar válidamente leyes inconstitucionales. Los jueces no son el mecanismo, pero son quienes deben establecer

\footnotetext{
${ }^{50}$ FERRERES: 2000: 37.

${ }^{51}$ Vid. ATIENZA y RUIZ MANERO: 2003: 724 y ss.
} 
cuando hay dudas al respecto si las normas promulgadas han respetado o no la regla que confiere el poder de legislar. Cuando se trata de lo que Atienza y Ruiz Manero denominan la validez regulativa, es decir, si el contenido de las normas vulneran o no lo dispuesto en normas de rango superior y, como es el caso, cuando dichas normas son los principios constitucionales, puede ser mucho menos claro cuándo la ley es inválida o no, pero la tarea del juez constitucional no es tan radicalmente diferente a la más ordinaria de determinar si, por ejemplo, una determinada autoridad actuó en el ámbito de su competencia material.

La cuarta razón es una aplicación del principio general de que la aceptabilidad de las medidas paternalistas depende de que las circunstancias permitan pensar en que el poder se ejercerá dentro de los límites y con la finalidad benevolente prevista. Dicho de otro modo, depende de que quepa hablar de un consentimiento hipotético racional a la medida ${ }^{52}$. Anteriormente, vimos como Mill defendía el mandato representativo acudiendo a la analogía entre el gobernante y el médico. Esta analogía es peligrosa porque bien podría fundar un despotismo benevolente, por ello Mill insiste en subrayar el poder que retiene el pueblo, esto es, el poder de cambiar de médico o, en términos políticos, de elegir a nuevos gobernantes en las elecciones. En el caso de los jueces constitucionales, de la misma manera, la aceptabilidad de su poder de decisión depende tanto de que les reconozcamos unas cualificaciones especiales para llevar a cabo la tarea de dilucidar cuándo el legislador se ha excedido de su competencia (el análogo al conocimiento que atesoran los médicos), como del poder que retenga el pueblo en relación con dichos jueces (el análogo a la posibilidad de elegir y cambiar de médico).

Con respecto a lo primero, bien entendida la tarea de los jueces constitucionales no cabe duda, a mi juicio, de la necesidad de contar con juristas expertos. John Rawls, considerando que el tribunal Supremo es el modelo de la razón pública, la describe de la siguiente manera:

...es tarea de los jueces intentar desarrollar y expresar, en sus opiniones razonadas, la mejor interpretación de la constitución que puedan usando su conocimiento de lo que exijan la constitución y los precedentes constitucionales. En este caso, la mejor interpretación es la que mejor cuadra con el cuerpo de esos materiales constitucionales y la que mejor justifica ese cuerpo en los términos de la concepción política de la justicia, o de una variante razonable de ella (...) El papel del tribunal aquí

\footnotetext{
${ }^{52}$ vid. ALEMANY: 2005: 413 y ss.
} 
es parte de la publicidad de la razón, y constituye un aspecto del amplio papel, también educativo, desempeñado por la razón pública $^{53}$.

Con respecto a lo segundo, es importante reparar en algunas de las diferencias esenciales que se han asignado tradicionalmente a las autoridades jurisdiccionales frente a las autoridades políticas ${ }^{54}$. De nuevo Tocqueville lúcidamente nos advierte de lo crucial de estas diferencias. En particular, este autor destaca que

La primera característica del poder judicial en todos los pueblos es su función de árbitro. Para que tenga lugar una acción por parte de los tribunales, es preciso que se produzca una protesta. Para que haya un juez, tiene que haber proceso. En tanto que una ley no origine oposición, el poder judicial no se ocupa de ella (...) Cuando se pronuncia sobre una ley sin partir de un proceso, se sale totalmente de su esfera e invade la del poder legislativo (...) El poder judicial violaría en cierto modo su naturaleza pasiva si tomara por sí mismo la iniciativa y se convirtiera en censor de las leyes ${ }^{55}$.

De ahí que cuando los jueces constitucionales deciden si el legislador ha ido más allá de su competencia o no, normalmente estarán haciendo prevalecer las opiniones sustentadas al respecto por alguna parte de la sociedad, pudiendo ser incluso la parte mayoritaria la que vence en su interpretación de la Constitución frente a una minoría recurrente. La imagen que mejor refleja esta situación es la del árbitro acordado por las partes en el pacto constituyente y no la imagen de la elite judicial actuando siempre de forma contramayoritaria. Este carácter pasivo de los jueces constituye un límite importante a su poder y, por tanto, un argumento a favor de la razonabilidad de aceptar dicho poder. Igualmente, con frecuencia se olvida que dichos jueces son nombrados a través de procedimientos que tratan de reflejar de alguna manera las mayorías democráticas: por ejemplo, propuestos por el jefe del ejecutivo pero con la posibilidad de veto por el legislativo.

De otro lado, al configurar el poder de los jueces constitucionales como una autoridad jurisdiccional y no política, con una tarea como la que se ha descrito, no sólo se admiten límites para la autoridad política sino también límites para la autoridad jurisdiccional. Dicho de otro modo, a los jueces constitucionales no se les suele reconocer la última palabra en

\footnotetext{
${ }^{53}$ RAWLS: 1995: 271.

${ }^{54}$ Un resumen de las mismas puede verse en AGUILÓ: 2000: 121 y ss.

${ }^{55}$ TOCQUEVILLE: 2002: 155 y 156.
} 
cualquier controversia, sino sólo con respecto a un tipo de ellas: las que pueden ser vistas como cuestiones de principios (constitucionales) y, por tanto, planteadas como preguntas con una respuesta binaria, de todo o nada, del tipo de "dada tal combinación de circunstancias ¿prevalece el principio A o el principio B?" 56 . Lo cual no quiere decir que el razonamiento que se espera de los jueces constitucionales sea totalmente ajeno a las consecuencias, pero le interesan las consecuencias de sus decisiones fundamentalmente en el sentido de “implicaciones jurídicas" de su decisión ${ }^{57}$.

\section{Conclusión}

Hasta aquí he tratado de mostrar, en primer lugar, que en muchas de las justificaciones de la rigidez constitucional, en sus diversos grados, y del control jurisdiccional de constitucionalidad, en sus diversas formas, se emplea un tipo de argumento con la forma del argumento que he denominado "paternalista". Dicho argumento hace aparecer la rigidez y el control como necesarios para proteger a los derechos y libertades fundamentales atendiendo a déficit probables de comprensión y/o voluntad en las eventuales mayorías parlamentarias. En segundo lugar, he señalado la importancia de advertir la ambigüedad de la concepción de las constituciones como mecanismos de precompromiso. De acuerdo con uno de sus significados, se afirma la existencia de un compromiso previo por parte de los constituyentes que tuvieron la intención de "atarse las manos". Así entendida, el alcance justificativo de dicha doctrina es muy limitado y presupone la defensa de una concepción originalista de la Constitución. De acuerdo con otro de sus significados, la doctrina del precompromiso alude a un modelo de racionalidad imperfecta y, en mi opinión, su alcance justificativo es mayor, ya que se orienta a presentar la rigidez constitucional como una necesidad para la garantía de los derechos fundamentales, pero ya no se trata de aludir a su vinculación a los compromisos previos sino del argumento paternalista. En tercer lugar, he defendido que, en relación con el control jurisdiccional de constitucionalidad, el uso del argumento paternalista no tiene necesariamente para los ciudadanos el carácter insultante que le asigna Waldron, ya que el paternalismo no se ejerce directamente sobre ellos sino sobre las mayorías parlamentarias y, con respecto a éstas, dependiendo de las circunstancias, dicho paternalismo puede considerarse como justificado.

\footnotetext{
${ }^{56}$ RUIZ MANERO: 2007: 90.

${ }^{57}$ Vid. MCCORMICK: 2005: 101.
} 
Sin embargo, hay que admitir que cuando de lo que se trata es de garantizar ciertos bienes primarios a los individuos de una sociedad a lo largo de las generaciones, con incertidumbre sobre las circunstancias cambiantes de la historia, sobre el grado de comprensión de esos mismos individuos sobre sus genuinos intereses, etc., no podemos estar seguros de que la opción por algún grado de rigidez en concreto y alguna particular forma de control jurisdiccional de constitucionalidad sea la mejor. En relación con lo primero, Bayón opina, por ejemplo, que "para quien haga suyo el ideal moral del coto vedado" el mejor mecanismo de protección sería un núcleo constitucional intangible de reglas bien determinadas, una posición que él mismo califica de constitucionalismo débil ${ }^{58}$. En relación con lo segundo, De Lora, por ejemplo, defiende una presunción fuerte a favor de la constitucionalidad de las leyes de manera que sólo se procediera a su anulación por parte de un Tribunal Constitucional por decisión unánime ${ }^{59}$. De esta manera, pareciera que nos vemos abocados en última instancia a apoyar nuestras conclusiones en juicios contrafácticos, los cuales no pueden producir sino insatisfacción por las dificultades de fundamentación que los mismos presentan. En todo caso, no es descartable que la rigidez constitucional y el control jurisdiccional de constitucionalidad, por su carácter instrumental, puedan arrojar resultados perniciosos: "estas mismas técnicas -advierte Aguiló- al servicio, por ejemplo, no de una expectativa considerada valiosa $\mathrm{y}$, por tanto, merecedora de ser protegida en forma de un derecho, sino de un privilegio (es decir, de una expectativa no valiosa y/o no justificada) resultan simplemente insoportables e irracionales" ${ }^{, 60}$.

Sin embargo, el excesivo énfasis en las ideas de "mecanismo de tipo estructural" o “diseño institucional” puede distorsionar nuestra visión del problema. A mi juicio, Aguiló acierta cuando sostiene que para garantizar una práctica jurídica y política respetuosa con los derechos

ello exige recurrir a conceptos dialécticos que apuntan hacia síntesis relativamente inestables (como ponderación, equilibrio, etc.) y al desarrollo de las actitudes adecuadas vinculadas a necesidades discursivas de justificación. Es decir, apuntan más hacia las exigencias deliberativas y argumentativas vinculadas a la idea de "vivir en constitución" que hacia las respuestas estructurales vinculadas a "tener una constitución" 61 .

\footnotetext{
${ }^{58}$ Vid. BAYÓN: 2000: 85.

${ }^{59}$ DE LORA: 2000: 50.

${ }^{60}$ AGUILÓ: 2008: 121.

${ }^{61}$ AGUILÓ: 2008: 127.
} 
Más adelante, el mismo autor, en relación con el problema de "el gobierno de los muertos" que parece implicar la rigidez constitucional señala

De nuevo, y sin extenderme mucho, en mi opinión, esta tensión entre quienes "se dieron una constitución" (los muertos) y quienes "tienen una constitución" (los vivos) tampoco es susceptible de recibir una respuesta estructural o definitiva. La síntesis armónica entre unos y otros sólo puede expresarse mediante nociones inestables y dialécticas como la de "continuidad de una práctica" que permita eliminar los términos indeseables, por un lado, de sometimiento al pasado y, por otro, de ausencia de garantía de los derechos (de estabilización de las expectativas relativas a los derechos). Nuevamente, al igual que en el caso anterior; la solución hay que buscarla apuntando hacia las exigencias deliberativas y argumentativas y el desarrollo de las actitudes adecuadas ${ }^{62}$.

No podemos esperar que un mecanismo o diseño institucional garantizador de los derechos produzca sus efectos de forma automática (no pueden operar como mecanismos de justicia procedimental perfecta). Todos ellos requieren de la aceptación por parte de los operadores jurídicos y de que se apliquen con sentido. Para quien, como Waldron, el mecanismo de la rigidez constitucional y los tribunales constitucionales se reducen a un puro sistema procedimental de decisión en manos de unos pocos jueces (lo cual, en su opinión, no se puede afirmar ni siquiera que haya arrojado buenos resultados prácticos), no cabe duda de que no son una buena idea ${ }^{63}$. El problema es que de esta manera se pide el principio: nada valioso se obtiene de lo que se ha vaciado previamente de valor.

La última conclusión que quiero presentar es que el hecho de que haya sociedades que viven en Constitución sin tener una constitución no puede utilizarse como un argumento contra la constitución formal, aunque nos muestra que la eficacia de los diseños institucionales debe medirse por su capacidad de generar límites internos, esto es, de generar una cultura jurídica respetuosa con los derechos. Por ello, una vez que se han refutado las objeciones de principio al constitucionalismo (fundamentalmente que presupone un paternalismo injustificado), la clave de la discusión está en si el proceso histórico de constitucionalización debe ser visto o no como un progreso en la extensión de esta cultura jurídica de respeto a los derechos. En mi opinión, éste es el caso y me atrevería a decir que la

\footnotetext{
${ }^{62}$ AGUILÓ: 2008: 128

${ }^{63}$ Vid. WALDRON, 2005, 344
} 
posición democrática puede sufrir la misma miopía que algunos ilustres pensadores, liberales y progresistas, mostraron en relación con el sentido y alcance de las "declaraciones de derechos".

\section{Referencias bibliográficas}

AGUILÓ, Josep. La Constitución del Estado Constitucional, Lima-Bogotá, Palestra-Temis, 2004.

AGUILÓ, Josep. Sobre Derecho y argumentación, Palma, Lleonard Muntaner, 2008.

; ATIENZA, Manuel; y RUIZ MANERO, Juan. Fragmentos para una teoría de la Constitución, Madrid, Iustel, 2007.

ALEMANY, Macario. El paternalismo jurídico, Madrid, Iustel, 2006.

AÑÓN, María José. Necesidades y derechos (Un ensayo de fundamentación), Madrid, Centro de Estudios Constitucionales, 1994.

ATIENZA, Manuel. El Derecho como argumentación, Barcelona, ed. Ariel, 2006.

BAYÓN, Juan Carlos. "Derechos, democracia y Constitución”, en Discusiones, 1, 2000, pp. 65-94.

DE LORA, Pablo. La interpretación originalista de la Constitución. Una aproximación desde la filosofía del Derecho, Madrid, BOE y CEPC, 1998.

“La posibilidad del constitucional thayeriano", en Doxa, 2000, pp. 49-75.

ELSTER, Jon. Ulises y las sirenas. Estudios sobre racionalidad e irracionalidad, t. c. Juan José Utrilla, México, Fondo de Cultura Económica, 1997 [ed. original: Ulises and the Sirens. Studies in Rationality and Irrationality, Camdridge University Press, Cambridge, 1984].

Ulises desatado. Estudios sobre racionalidad, precompromiso y restricciones, t. c. de Jordi Mundó, Barcelona, Gedisa, 2002 [ed. original: Ulises Unbound. Studies in Rationality, Precommitment, and Constrains, The Press Syndicate of the University of Cambridge, 2000).

FERRAJOLI, Luigi. "Democracia constitucional y derechos fundamentales. La rigidez de la Constitución y sus garantías". En: FERRAJOLI, Luigi; MORESO, José Juan; y ATIENZA, Manuel. La teoría del derecho en el paradigma constitucional, Fundación Coloquio Jurídico Europeo, Madrid, 2008.

FERRERES, Victor. "Una defensa de la rigidez constitucional", en Doxa, 23, 2000, pp. 29-47. 
GARZÓN Valdés, Ernesto. "Necesidades básicas, deseos legítimos y legitimidad política en la concepción ética de Mario Bunge", en Derecho, ética y política, Madrid, Centro de Estudios Constitucionales, 1993 , pp. 417-435.

"Representación y democracia", en Derecho, ética y política, Madrid, Centro de Estudios Constitucionales, 1993b, pp. 631-650.

'Desde la 'modesta propuesta' de J. Swift hasta las 'casas de

engorde' (Algunas consideraciones acerca de los derechos de los niños), Doxa, 15-16, vol. II, 1994, pp. 731-744.

GUASTINI, Ricardo. "La constitucionalización del ordenamiento jurídico: el caso italiano", en Carbonell, Miguel; Neoconstitucionalismo(s), Trotta, Madrid, 2003.

HART, H.L.A.. El concepto de Derecho, t. c. de Genaro R. Carrió, Buenos Aires, Abeledo-Perrot, 1963 [ed. Original: The Concept of Law, Oxford University Press, 1961].

. Law, Liberty and Morality, Stanford University Press, 1963.

HOLMES, Stephen. "Precommmitment and the Paradox of Democracy", en Constitutionalism and Democracy, Jon Elster \& Rune Slagstad (eds.), Cambridge, Cambridge University Press, 1988, pp. 195-249.

LAPORTA, Francisco. “El ámbito de la Constitución”, en Doxa, 24, 2001.

El imperio de la ley. Una visión actual, Madrid, Trotta, 2007.

LIFANTE, Isabel. "Interpretación y modelos de derecho. Sobre el papel de la intención en la interpretación jurídica”, en Doxa, 22, 1999, pp. 171-193..

MILL, John Stuart. "Recensión del volumen 1 de "La democracia en América", en Sobre la libertad y comentarios a Tocqueville, t. c. Cristina García Gay, Madrid, Espasa-Calpe, 1991 [ed. original: "Mill's Reviews of Democracy in America", London (and Westminster) Review, 1835].

Sobre la libertad, t. c. Pablo de Azcárate, Madrid, Alianza Editorial, 1999 [ed. original: On liberty, London, 1859].

MORESO, José Juan. "Derechos y justicia procesal imperfecta", Discusiones, 1, 2000, pp. 15-51.

La Constitución: un modelo para armar, Madrid, Marcial Pons, 2009.

RUIZ MANERO, Juan. "Una tipología de las normas constitucionales", en Aguiló, Josep; Atienza, Manuel; y Juan Ruiz Manero; Fragmentos para una teoría de la Constitución, Madrid, Iustel, 2007.

TOCQUEVILlE, Alexis de. La democracia en América, 1, t. c. Dolores Sánchez de Aleu, Madrid, Alianza Editorial, 2002a [ed. original: De la démocratie en Amerique, París, 1850]. 
La democracia en América, 2, t. c. Dolores Sánchez de Aleu, Madrid, Alianza Editorial, 2002b [ed. original. De la démocratie en Amerique, París, 1850].

WALDRON, Jeremy. Derecho y desacuerdos, t. c. José Luis Martí y Agueda Quiroga, Madrid, Marcial Pons, 2005a [ed. original: Law and Disagreement, Oxford, Oxford University Press, 1999].

ZIMMERLING, Ruth. "La pregunta del tonto y la respuesta de Gauthier", en Doxa, 6, 1989, pp. 39-76.

Artigo recebido em 19 de julho de 2013. Artigo aprovado para publicação em 10 de outubro de 2013.

DOI: $10.11117 / 1982-4564.06 .14$ 